TITLE:

\title{
Hyphal length in the forest floor and soil of subtropical, temperate, and subalpine forests
}

$\operatorname{AUTHOR}(\mathrm{S}):$

Osono, Takashi

\section{CITATION:}

Osono, Takashi. Hyphal length in the forest floor and soil of subtropical, temperate, and subalpine forests. Journal of Forest Research 2014, 20(1): 69-76

\section{ISSUE DATE:}

2014-09-20

URL:

http://hdl.handle.net/2433/200681

\section{RIGHT:}

The final publication is available at Springer via http://dx.doi.org/10.1007/s10310-0140461-2.; This is not the published version. Please cite only the published version.; この論 文は出版社版でありません。引用の際には出版社版をご確認ご利用ください。 
1 Hyphal length in the forest floor and soil of subtropical, temperate, and subalpine

2 forests

3

4 Takashi Osono

5

6 T. Osono

7 Center for Ecological Research, Kyoto University, Otsu, Shiga 520-2113 Japan

8 e-mail: tosono@ecology.kyoto-u.ac.jp

10 AbstractFungi are a major component of soil biota in terrestrial ecosystems of

11 various climatic regions, but few studies have compared the effects of soil layers

12 and seasons on their abundance between sites with different humus forms and

13 climatic conditions. In the present study, the hyphal length in the forest floor and

14 soil was investigated in subtropical (ST), cool temperate (CT), and subalpine (SA)

15 forests in Japan with an agar film method. The primary aim was to describe the

16 seasonal variations in hyphal length in different layers of mull and moder humus

17 forms in forests of these three climatic regions. The total hyphal length was 
18 generally higher in CT than in ST and SA and decreased with the soil depth.

19 Seasonal changes in total hyphal length were observed in ST and in the lower

20 slope of CT where mull humus developed. The length of darkly pigmented hyphae

21 and its proportion relative to the total hyphal length were higher at the upper

22 slope of CT (moder humus) than at the other sites and was in the order: $\mathrm{F}>\mathrm{L}>\mathrm{A}$

23 layers. Clamp-bearing hyphal length in Basidiomycota accounted for as much as

$2419 \%$ of the total hyphal length and decreased with the depth of the forest floor and

25 soil in all study sites. Seasonal changes of hyphal length and the layer $\times$ month

26 interaction were significant on mull but not on moder humus, suggesting that

27 hyphal length was more sensitive to season in mull than in moder humus.

28

29

Keywords

Climate • Fungi • Fungal biomass - Mycelia - Seasonal

30

change

31

32

Introduction

34 Fungi are a major component of soil biota in terrestrial ecosystems, representing 
35 large pools of nutrients, controlling carbon and nutrient cycling in soils as

36 decomposers and mutualistic root-symbionts, and involved in soil food webs (Dix

and Webster 1995; Boddy et al. 2008). The abundance and species composition of

fungal communities in litter and soil can be indicative of the functional roles of

and species composition concurrently with any single method. Moreover, a

number of factors contribute to the complexity in measuring fungal communities

in soils. Consequently, a variety of techniques have been described for quantifying

fungal biomass in litter and soil (Newell 1992). Commonly used methods to

measure fungal biomass include direct microscopic visual observations of hyphal

length and biochemical assays for fungal marker molecules, such as chitin and ergosterol. Of these methods, the direct microscopic techniques can be biased by a degree of observer subjectivity, but they allow for visual classification of hyphal types, such as hyaline, darkly pigmented, and clamp-bearing ones, which often can help interpreting the composition of fungal community (Frankland 1982;

50 Kjøller and Struwe 1982; Osono 2007; van der Wal et al. 2009). 
52 direct observation methods in litter and soil (Kjøller and Struwe 1982; Holden et

53 al. 2013) and in litter at initial stages of decomposition (e.g. Berg and Söderström

54 1979; Fioretto et al. 1998; Osono and Takeda 2001; Osono 2005). To date, the

55 variations of hyphal length with soil layer, season, humus form, and climatic

56 region have been examined separately. To the knowledge of the author, however,

57 few studies have investigated the effects of soil layer and season on hyphal length

58 at the same time and compared them between sites with different humus forms

59 and climatic conditions (Osono 2011). The purpose of the present study was to investigate the hyphal length in

61 the forest floor and soil of subtropical, cool temperate, and subalpine forests in Japan with an agar film method. The primary goal was to describe the seasonal

63 variations in hyphal length in different layers of mull and moder humus forms in

64 forests of these three climatic regions. Soil samples were collected at each study

65 forest over a snow-free period to evaluate the relative effects of layer, season, and

66 their interactions on total, darkly pigmented, and clamp-bearing hyphal lengths. Previous data of hyphal lengths in the forest floor and soils of different climatic regions were then summarized to explore whether hyphal length in litter and soil 
69 would exhibit patterns along a latitudinal or climatic gradient.

70

71 Materials and methods

72

73 Study site

74

75 Samples were collected from three sites in Japan: a subtropical forest (ST), a cool

76 temperate forest (CT), and a subalpine forest (SA). Table 1 shows the location,

77 climatic condition, vegetation, and data of forest floor measurements of the study

78 sites. ST was located in the northern part of Okinawa Island in southern Japan. A

79 study plot was established in a subtropical broadleaved forest dominated by

80 Castanopsis sieboldii (Makino) Hatusima (Fagaceae) and Schima wallichii (DC.)

81 Korthals (Theaceae) in the Yona Experimental Forest of the University of the

82 Ryukyus. CT was located in Kyoto, central Japan. Two study plots were

83 established on the lower and upper parts of a northwest-facing slope

84 (approximately $200 \mathrm{~m}$ long; Osono et al. 2008a) in a cool temperate forest

85 dominated by Fagus crenata Bl. and Quercus crispula Bl. (Fagaceae) in the Ashiu 
86 Experimental Forest of Kyoto University. SA was located on Mt. Ontake, Gifu,

87 central Japan. A study plot was established there in a subalpine forest dominated

88 by Abies mariesii Masters, Abies veitchii Lindley, Picea jezoensis var. hondoensis

89 (Sieb. et Zucc.) Carrière (Pinaceae), and Betula ermanii Cham. (Betulaceae).

90 Monthly temperature data of the sites are shown in Fig. 1. The three sites differed

91 in mean annual temperature and seasonal changes in air temperature, but they

92 received similar amounts of precipitation annually (Table 1, Fig. 1). The mean

93 annual temperature and annual precipitation of the year when the samplings

94 were conducted were $21.1^{\circ} \mathrm{C}$ and $3167 \mathrm{~mm}$ in $2007 \mathrm{in} \mathrm{ST,} 9.8^{\circ} \mathrm{C}$ and $2548 \mathrm{~mm}$ in

952001 in $\mathrm{CT}$, and $2.0^{\circ} \mathrm{C}$ and $2299 \mathrm{~mm}$ in 2008 in SA. The study sites experience a

96 rainy season from May to June in ST and from June to July in CT and SA. Snow

97 covers the forest floor of CT from December to April and that of SA from

98 mid-November to early June.

99

100 Sample collection

102 A study plot of $50 \times 10 \mathrm{~m}\left(500 \mathrm{~m}^{2}\right)$ was laid out in each of ST, CT (upper), CT 
103 (lower), and SA sites and was divided into 125 grids of $2 \times 2 \mathrm{~m}$. Samples of L, F,

104 and A layer materials were collected from the four plots and used for the

105 estimation of hyphal length. Collection of the samples was performed six times: in

106 March, May, July, September, and November 2007 and in January 2008 in ST,

107 four times: in May, July, September, and November 2001 in CT, and three times:

108 in June, August, and October 2008 in SA. On each sampling occasion, 10 (ST and

109 SA) or five (CT lower and upper) grids were randomly chosen from the 125 grids

110 in each plot, and one soil block $(20 \times 20 \mathrm{~cm}$ in area $)$ was collected from the center

111 of each grid. The block was divided into L and A layers for ST and CT (lower) and

112 L, F, and A layers for CT (upper) and SA, preserved in vinyl bags, and taken to the

113 laboratory. The F layer in ST and CT (lower) developed poorly and was not

114 included in the measurement of hyphal length. The A layer materials $(3 \mathrm{~cm}$ in

115 depth) were collected from the surface of A layer because the depth of A layer

116 varied between the sites.

Thus, a total of 310 samples were used for the present study, including

$118120(6$ dates $\times 2$ layers $\times 10$ replicates $)$ from ST, $40(4$ dates $\times 2$ layers $\times 5$

119 replicates) from CT (lower), 60 (4 dates $\times 3$ layers $\times 5$ replicates) from CT (upper), 
120 and 90 (3 dates $\times 3$ layers $\times 10$ replicates $)$ from SA. Samples were preserved in a

121 refrigerator at $4^{\circ} \mathrm{C}$ and processed within 48 hours after sampling. The $\mathrm{L}$ layer

122 materials were fragmented using a blender to make particles of approximately $5 \times$

$1235 \mathrm{~mm}$ in area, and $\mathrm{F}$ and A layer materials were passed through a $2-\mathrm{mm}$ sieve to

124 exclude plant roots and coarse fragments, before a portion of the samples was

125 used for hyphal length estimation.

127 Hyphal length estimation

129 Hyphal lengths in L, F, and A layer materials were estimated using the agar film

130 method of Jones and Mollison (1948), but with several modifications (Osono et al.

131 2006). One gram of a sample was homogenized in a blender at $10,000 \mathrm{rev} / \mathrm{min}$ in

$13249 \mathrm{ml}$ of distilled water for $3 \mathrm{~min}$. The suspension $(20 \mathrm{ml})$ was diluted with $20 \mathrm{ml}$

133 of molten agar solution (final concentration 1.5\%) and mixed at low speed on a

134 magnetic stirring plate. Three agar plates were prepared for each suspension in a

135 haemocytometer (0.1 $\mathrm{mm}$ depth), transferred to glass slides, and dried for 24

136 hours. The films were stained with fluorescent brightener (FB) for one hour. FB 
137 binds to chitin in fungal cell walls (West 1988) and enables visualization of all

138 hyaline hyphae that are live or ghosts (empty). The stained films were mounted

139 between slides and coverslips with one drop of immersion oil (type DF, Cargille

140 Laboratories, Inc., Cedar Grove, NJ, USA) and examined with a Nikon

141 Microphot-SA epifluorescent microscope equipped with a high-intensity mercury

142 light source. A Nikon UV-1A filter cube was used for examination of FB-stained

143 hyphae. Darkly pigmented hyphae that were not stained with FB were observed

144 by bright field microscopy. Microscope fields were selected randomly and 25 fields

145 were observed for each slide at 1000× magnification. Hyphal lengths were

146 estimated using an eyepiece grid and a grid-intersection method (Olson 1950).

147 Total hyphal length was calculated as the sum of the lengths of hyaline hyphae

148 stained with FB and darkly pigmented hyphae. Hyphae with clamp connection

149 were classified into Basidiomycota, in spite of the fact that the hyphal length may

150 have been underestimated because the frequency of clamp formation varies

151 between species. Separate litter samples were oven-dried to a constant mass at

$15240^{\circ} \mathrm{C}$ and used to measure oven-dry weight. 
154 Statistical analysis

155

156 The generalized linear model (GLM) was used to evaluate the difference in hyphal

157 length using layer, month, and the layer $\times$ month interaction as independent

158 variables. Tukey's HSD test was performed for multiple comparisons. JMP 6.0 for

159 Macintosh was used to perform these analyses.

160

161 Results

162

163 Total hyphal length

164

165 The mean total hyphal length was generally higher in CT than in ST and SA, and

166 decreased with the depth of the forest floor and soil (Fig. 2). In ST, the mean total

167 hyphal length ranged from 3696 to $6311 \mathrm{~m} / \mathrm{g}$ in the L layer and from 1061 to 1366

$168 \mathrm{~m} / \mathrm{g}$ in the A layer (Fig. 2). Total hyphal length in the L layer was significantly

169 higher than that in the A layer (Table 2). The effects of month and layer $\times$ month

170 interaction were also significant (Table 2), with total hyphal length in the L layer 
171 being especially elevated in November (Fig. 2).

172

The mean total hyphal length in CT was generally greater at the upper

173 than at the lower CT site (Fig. 2). In the L layer, it ranged from 8259 to $12172 \mathrm{~m} / \mathrm{g}$

174 at the lower site and from 12768 to $18733 \mathrm{~m} / \mathrm{g}$ at the upper site; in the F layer, it

175 ranged from 8243 to $10051 \mathrm{~m} / \mathrm{g}$ at the upper site; and in the A layer, it ranged

176 from 530 to $2022 \mathrm{~m} / \mathrm{g}$ at the lower site and from 2795 to $3864 \mathrm{~m} / \mathrm{g}$ at the upper site.

177 Total hyphal length in the L layer was significantly higher than that in the A layer

178 at both the upper and lower sites (Table 2). Total hyphal length at the lower site

179 also varied significantly with month (Table 2), being higher in May than in June

180 and September (Fig. 2).

181

The mean total hyphal length in SA ranged from 6061 to $6604 \mathrm{~m} / \mathrm{g}$ in the

182 L layer, from 3982 to $4769 \mathrm{~m} / \mathrm{g}$ in the $\mathrm{F}$ layer, and from 871 to $1090 \mathrm{~m} / \mathrm{g}$ in the A

183 layer (Fig. 2). The differences among the layers were statistically significant,

184 whereas significant variation among the months was not observed (Table 2).

185

186 Darkly pigmented hyphal length 
188 Overall, darkly pigmented hyphal length was greater at CT (upper) than at the

189 other sites, and decreased in the order: F (if available) > L > A layer (Fig. 3). In ST,

190 the mean darkly pigmented hyphal length ranged from 361 to $859 \mathrm{~m} / \mathrm{g}$ in the $\mathrm{L}$

191 layer and from 54 to $162 \mathrm{~m} / \mathrm{g}$ in the A layer (Fig. 3). Darkly pigmented hyphal

192 length was significantly greater in the $\mathrm{L}$ than in the A layer, and varied with

193 month (Table 2). It accounted for $5 \%$ to $15 \%$ of the total hyphal length, and the

194 proportion did not vary significantly with either layer or month (Table 2). $3039 \mathrm{~m} / \mathrm{g}$ in the L layer at the upper and lower sites, from 2932 to $3212 \mathrm{~m} / \mathrm{g}$ at the

197 upper site, and from 237 to $827 \mathrm{~m} / \mathrm{g}$ in the A layer at the upper and lower sites

198 (Fig. 3). Darkly pigmented hyphal length was significantly different in the order:

$199 \mathrm{~L}>$ A layer at the lower site and $\mathrm{F}>\mathrm{L}>\mathrm{A}$ layer at the upper site, and it did not

200 vary significantly with month at either site (Table 2). The proportion of darkly

201 pigmented hyphal length with respect to the total hyphal length was significantly

202 different between the layers at both the upper and lower sites (Table 2). It was

$20338 \%$ to $53 \%$ in the A layer at the lower site and $32 \%$ to $37 \%$ in the $\mathrm{F}$ layer at the

204 upper site, whereas it was between $8 \%$ and $26 \%$ in the L layer at the lower site 
205 and in the L and A layers at the upper site (Fig. 3).

206

The mean darkly pigmented hyphal length in SA ranged from 806 to

$2071367 \mathrm{~m} / \mathrm{g}$ in the L layer, from 1432 to $1799 \mathrm{~m} / \mathrm{g}$ in the F layer, and from 124 to 425

$208 \mathrm{~m} / \mathrm{g}$ in the A layer (Fig. 3), and the differences between the layers were

209 statistically significant (Table 2). Darkly pigmented hyphal length accounted for

$21030 \%$ to $45 \%$ of the total hyphal length in the F layer, which was significantly

211 higher than that in the L layer (14\% to 23\%) (Table 2). This proportion was

212 significantly higher in June than in August or October (Fig. 3, Table 2).

213

214 Clamp-bearing hyphal length

215

216 The mean clamp-bearing hyphal length in ST ranged from 198 to $906 \mathrm{~m} / \mathrm{g}$ in the L

217 layer and from 2 to $89 \mathrm{~m} / \mathrm{g}$ in the A layer (Fig. 4), and the difference between the L

218 and A layers was statistically significant (Table 2). The effects of month and the

219 layer $\times$ month interaction were also significant (Table 2), indicating that

220 clamp-bearing hyphal length in L layer was significantly elevated, especially in

221 November (Fig. 4). Clamp-bearing hyphal length accounted for 4\% to $13 \%$ of the 
222 total hyphal length in the $\mathrm{L}$ layer, and for $0 \%$ to $6 \%$ in the A layer, and the

223 difference between the L and A layers was statistically significant (Table 2).

224 The mean clamp-bearing hyphal length at the lower site in CT ranged

225 from 330 to $1049 \mathrm{~m} / \mathrm{g}$ in the L layer and was not detected in the A layer, whereas

226 at the upper site in CT it ranged from 435 to $3792 \mathrm{~m} / \mathrm{g}$ in the L layer, 319 to 1130

227 in the F layer, and 0 to $100 \mathrm{~m} / \mathrm{g}$ in the A layer (Fig. 4). Clamp-bearing hyphal

228 length and its proportion relative to the total hyphal length was significantly

229 higher in the L than in the $\mathrm{F}$ and A layers both at the upper and lower sites and

230 was significantly higher in November than in May at the upper site (Table 2).

231 Clamp-bearing hyphal length generally accounted for $0 \%$ to $13 \%$ of the total

232 hyphal length and increased to $19 \%$ at the upper site in November (Fig. 4).

233

The mean clamp-bearing hyphal length in SA ranged from 836 to 1012

$234 \mathrm{~m} / \mathrm{g}$ in the L layer, from 130 to $910 \mathrm{~m} / \mathrm{g}$ in the $\mathrm{F}$ layer, and from 0 to $207 \mathrm{~m} / \mathrm{g}$ in the

235 A layer (Fig. 4), and the differences between the layers were statistically

236 significant (Table 2). Clamp-bearing hyphal length accounted for $0 \%$ to $19 \%$ of the

237 total hyphal length (Fig. 4). 


\section{Discussion}

241 The values of total hyphal lengths in the present study fell within the range of

242 those previously reported in forests of Japan (Table S1 in Electronic

243 Supplementary Material) and other regions (summarized in Kjøller and Struwe

244 1982). The mean total hyphal lengths in the L layer of ST, CT, and SA correspond

to $9.6,23.7$, and $11.9 \mathrm{mg} / \mathrm{g}$, respectively, calculated with the conversion factors of:

246 the radius of hyphae (r) of $2 \mu \mathrm{m}$, the dry matter proportion of hyphae $\left(\mathrm{dm}_{\mathrm{r}}\right)$ of 0.1 ,

247 and the density of hyphae $\left(\mathrm{d}_{\mathrm{f}}\right)$ of $1.5 \mathrm{~g} / \mathrm{cm}^{3}$ (Kjøller and Struwe 1982). These length

248 estimates are again within the range of those previously reported (Kjøller and

249 Struwe 1982). There have been few estimates of the length of darkly-pigmented or

250 clamp-bearing hyphae, but the values in the present study were consistent with

251 those previously reported in Japan (Table S1). Similarly, Bååth and Söderström

252 (1977) reported that the length of darkly pigmented and clamp-bearing hyphae in

253 a Swedish coniferous forest ranged from 100 to $3500 \mathrm{~m} / \mathrm{g}$ and from 20 to $1300 \mathrm{~m} / \mathrm{g}$,

254 respectively, and accounted for $14 \%$ to $27 \%$ and $2 \%$ to $13 \%$ of the total hyphal

255 length, respectively. The results of the present study (Fig. 2) are consistent with 
256 the statement of Frankland (1982) that fungal mycelia are less concentrated in

257 mull with a thin accumulation of litter than in mor and moder with

258 well-developed organic layers.

259

The lengths of total and clamp-bearing hyphae decreased with the depth

260 of soil horizons in the present study (Figs. 2 and 4), which is in agreement with

261 previous reports (Ruscoe 1971; Hunt and Fogel 1983). These vertical patterns are

262 primarily attributable to the decrease in carbon content with depth (Kjøller and

263 Struwe 1982). In contrast, darkly pigmented hyphal length increased in F layers

264 of moder humus [i.e. in CT (upper) and SA] (Fig. 3). Bååth and Söderström (1977)

265 and Osono et al. (2003) also reported higher values of darkly pigmented hyphal

266 length in deeper soil layers. Decomposition experiments have also demonstrated

267 an increase in the length and/or the proportion of darkly pigmented hyphae

268 during litter transformation (Osono 2005; Osono et al. 2014). Osono et al. (2006)

269 found that incubation of needle litter beneath the $\mathrm{L}$ layer resulted in a

270 significantly greater amount of darkly pigmented hyphae than incubation of the

271 same litter on the surface of the L layer. Suggested underlying mechanisms of an

272 increase of darkly pigmented hyphae thus should include the higher potential of 
273 dematiaceous fungi to colonize litter in deeper layers (e.g. Tokumasu 1998) and

274 the slow turnover of recalcitrant melanized hyphae (Butler and Day 1998).

275 Relatively high values of darkly pigmented hyphal length and its proportion (29\%

276 to $42 \%$ ) relative to the total length were found in needle litter of Chamaecyparis

277 obtusa and in arctic substrates (Table S1). This suggests that darkly pigmented

278 hyphae can increase under stress of nutrients (e.g. in needle litter) or

279 environmental conditions (e.g. low temperatures or freezing), possibly in

280 association with the stress-resistant nature of melanized hyphae (Butler and Day

281 1998).

282

The total hyphal length in the L layer increased significantly in

283 November in ST and in May in CT (lower) (Fig. 2), where mull humus developed

284 (Table 1). Previous studies already showed an increase of total hyphal length in

285 spring and autumn and attributed it to favorable climatic (moisture and

286 temperature) and nutrient factors for fungal growth (Ruscoe 1971; Bååth and

287 Söderström 1977). A marked increase in clamp-bearing hyphal length and its

288 proportion relative to the total length in CT (upper) (Fig. 4) may be due to an

289 increase in litter-decomposing and/or mycorrhizal basidiomycetes. A concomitant 
290 increase in the occurrence of fruiting bodies of litter-decomposing and mycorrhizal

291 basidiomycetes was also observed in that November in CT (Osono unpubl.).

292 Ruscoe (1971) also reported an autumn increase in clamp-bearing hyphal length

293 in soil of a pure stand of Nothofagus truncata, but the generality and ecological

294 significance of the autumn flush of basidiomycetes remain unclear, mainly due to

295 the lack of relevant studies. Limitations of the present study should also be noted

296 as the field surveys were performed for different single years at the three sites

297 and only for snow-free periods at CT and SA.

298 Generally, the effects of layer of the forest floor were more marked on the

299 total, darkly pigmented, and clamp-bearing hyphal lengths than the month of

300 sampling at study sites (Table 2). Interestingly, the seasonal changes of total

301 hyphal length were significant on mull humus at ST and CT (lower) but not on

302 moder humus at CT (upper) and SA (Table 2). The effect of layer $\times$ month

303 interaction on total, darkly pigmented, and clamp-bearing hyphal length was also

304 significant only at ST and CT (lower). These results suggest that hyphal length in

305 L layer was more sensitive to season in mull than in moder soils. Possible explanations for this sensitivity are the amount and the turnover of forest floor 
307 materials. The lower amount and the faster turnover of the forest floor in mull

308 soils (Tsukamoto 1996) may lead to more variable hyphae length than in moder

309 humus.

310

When data of hyphal length in the forest floor and soils of Asian forests

311 and Canadian arctic tundra examined with the same direct observation method

312 were plotted against mean annual temperatures (Table S1), peaks of the total,

313 darkly pigmented, and clamp-bearing hyphal length in temperate regions would

314 be implied (Fig. S1). It is difficult, however, to gain insights into climatic patterns

315 of hyphal length, as data are still lacking in soils of other than temperate regions.

316 For example, Widden and Parkinson (1979) reported that total hyphal length in

317 Canadian tundra soils reached $2228 \mathrm{~m} / \mathrm{g}$, whereas Robinson et al. (1996)

318 summarized the data of total hyphal length in soils and dead plant tissues on

319 tundra soils and reported that these ranged from 4 to $9600 \mathrm{~m} / \mathrm{g}$ dry soil. Further

320 efforts are needed to measure hyphal lengths in various soils, especially of

321 tropical regions.

322

323 Acknowledgments

I thank Dr. A. Takashima and staff at the Yona 
324 Experimental Forest, University of the Ryukyus, for help with fieldwork at ST;

325 the staff at Ashiu Experimental Forest, Kyoto University, for help with fieldwork

326 at CT; and Dr. Elizabeth Nakajima for critical reading of the manuscript. This

327 study received partial financial support from the Ministry of Education, Culture,

328 Sports, Science, and Technology of Japan (MEXT) (No. 19780114), The Sumitomo

329 Foundation, Nissan Global Foundation, Nippon Life Inst. Foundation, and Grants

330 for Excellent Graduate Schools, MEXT, Japan (12-01) to Kyoto University.

References

333

334 Bååth E, Söderström BE (1977) Mycelial lengths and fungal biomasses in some central Sweden. Swedish Coniferous Forest Project, Technical Report $13: 1-45$

338 Berg B, Söderström B (1979) Fungal biomass and nitrogen in decomposing Scots pine needle litter. Soil Biol Biochem 11:339-341

340 Boddy L, Frankland JC, van West P (2008) Ecology of Saprotrophic 
342 Butler MJ, Day AW (1998) Fungal melanins: a review. Can J Microbiol

344 Dix NJ, Webster J (1995) Fungal Ecology. Chapman \& Hall, London

345 Enoki T (2003) Microtopography and distribution of canopy trees in a subtropical evergreen broad-leaved forest in the northern part of Okinawa Island, Japan. Ecol Res 18:103-113

348 Fioretto A, Musacchio A, Andolft G, Virzo de Santo A (1998) Decomposition dynamics of litters of various pine species in a Corsican pine forest. Soil Biol Biochem 30:721-757

351 Frankland JC (1982) Biomass and nutrient cycling by decomposer basidiomycetes. In: Frankland JC, Hedger JN, Swift Mj (eds) Decomposer Basidiomycetes, Their Biology and Ecology. Cambridge University Press, Cambridge, pp microorganisms in litter decomposition and soil formation. 
358 Holden SR, Gutierrez A, Treseder KK (2013) Soil fungal communities, extracellular enzyme activities, and litter decomposition across a fire chronosequence in Alaskan boreal forests. Ecosystems 16:34-46

361 Hunt GA, Fogel R (1983) Fungal hyphal dynamics in a western Oregon 362 Douglas-fir stand. Soil Biol Biochem 15:641-649

363

Jones PCT, Mollison JE (1948) A technique for the quantitative estimation of soil 364 microorganisms. J Gen Microbiol 2:54-69

365

Kjøller A, Struwe S (1982) Microfungi in ecosystems: fungal occurrence and 366 activity in litter and soil. Oikos 39:391-422

Koide K, Osono T, Takeda H (2005) Fungal succession and decomposition of Camellia japonica leaf litter. Ecol Res 20:599-609

369

Mori A, Mizumachi E, Osono T, Doi Y (2004) substrate-associated seedling recruitment and establishment of major conifer species in an old-growth subalpine forest in central Japan. For Ecol. Manag 196:287-297

372 Newell SY (1992) Estimating fungal biomass and productivity in decomposing litter. In: Carroll GC, Wicklow DT (eds) The Fungal Community: Its 
376 Olson FCW (1950) Quantitative estimates of filamentous algae. T Am Microsc Soc

$69: 272-279$

378

Osono T (2005) Colonization and succession of fungi during decomposition of Swida controversa leaf litter. Mycologia 97:589-597

380 Osono $\mathrm{T}$ (2007) Ecology of ligninolytic fungi associated with leaf litter decomposition. Ecol Res 22:955-974

382 Osono $\mathrm{T}$ (2011) Diversity and functioning of fungi associated with leaf litter decomposition in Asian forests of different climatic regions. Fun Ecol $4: 375-385$

385 Osono T, Takeda H, (2001) Organic chemical and nutrient dynamics in decomposing beech leaf litter in relation to fungal ingrowth and succession during three year decomposition processes in a cool temperate deciduous forest in Japan. Ecol Res 16:649-670 and species composition of fungal communities in a temperate forest affected by excreta of the Great Cormorant Phalacrocorax carbo. Soil Biol 
393 Osono T, Ono Y, Takeda H (2003) Fungal ingrowth on forest floor and decomposing needle litter of Chamaecyparis obtusa in relation to resource availability and moisture condition. Soil Biol Biochem

397 Osono T, Hirose D, Fujimaki R (2006) Fungal colonization as affected by litter 398 depth and decomposition stage of needle litter. Soil Biol Biochem $38: 2743-2752$

Osono T, Takeda H (2007) Microfungi associated with Abies needles and Betula leaf litter in a subalpine coniferous forest. Can J Microbiol 53:1-7

402 Osono T, Takeda H, Azuma JI (2008a) Carbon isotope dynamics during leaf litter decomposition in a cool temperate forest with reference to lignin fractions.

404 Ecol Res 23:51-55

405 Osono T, Ishii Y, Takeda H (2008b) Fungal colonization and decomposition of Castanopsis sieboldii leaves in a subtropical forest. Ecol Res 23:909-917

407 Osono T, Ishii Y, Takeda H, Seramethakun T, Khamyong S, To-Anun C, Hirose D, 
decomposition on Shorea obtusa leaves in a tropical seasonal forest in northern Thailand. Fungal Diversity 36:101-119

Osono T, Hobara S, Hishinuma T, Azuma JI (2011) Selective lignin decomposition and nitrogen mineralization in forest litter colonized by Clitocybe sp. Eur J Soil Biol 47:114-121

414 Osono T, Ueno T, Uchida M, Kanda H (2012) Abundance and diversity of fungi in relation to chemical changes in arctic moss profiles. Polar Sci 6:121-131 and decomposition of leaves and stems of Salix arctica on deglaciated moraines in high-Arctic Canada. Polar Sci 8:in press

Robinson CH, Borisova OB, Callaghan TV, Lee JA (1996) Fungal hyphal length in Polar Biol 16:71-74

422 litter of Dryas octopetala in a high-Arctic polar semi-desert, Svalbard. Mull and moder types humus in a broad-leaved forest. Bull Kyoto Univ 
427

428

430

Tsukamoto J (1996) Soil macro-invertebrates and litter disappearance in a Japanese mixed deciduous forest and comparison with European deciduous forests and tropical rainforests. Ecol Res 11:35-50

van der Wal A, Bloem J, Mulder C, de Boer W (2009) Relative abundance and activity of melanized hyphae in different soil ecosystems. Soil Biol observations on decomposing litter in mor humus form in a subalpine coniferous forest. Ecol Res 12:289-300

Tokumasu S (1998) Fungal successions on pine needles fallen at different seasons: the succession of surface colonizers. Mycoscience 39:417-423 
444 Widden P, Parkinson D (1979) Populations of fungi in a high arctic ecosystem. Can 
1 Figure legends.

2

3 Fig. 1. Seasonal changes in air temperature at the study sites. $\square$, subtropical (ST,

4 Okinawa); O, cool temperate (CT, Kyoto); $\boldsymbol{\Delta}$, subalpine forest (SA, Gifu). Values

5 are long-term averages for 22 to 35 years.

6

$7 \quad$ Fig. 2. Total hyphal length in soil layers. Values are mean \pm standard errors. $\square, \mathrm{L}$

8 layer; $\mathrm{O}$ layer; $\boldsymbol{\Delta}$, A layer. Note that the scales of the Y-axis are not consistent

9 between the sites.

10

11 Fig. 3. Darkly pigmented hyphal length (upper) and its proportion relative to the

12 total hyphal length (lower) in soil layers. Values are mean \pm standard errors.

13 Symbols are as in Fig. 2. Note that the scales of the Y-axis are not consistent

14 between the sites.

16 Fig. 4. Clamp-bearing hyphal length (upper) and its proportion relative to the 
1 total hyphal length (lower) in soil layers. Values are mean \pm standard errors.

2 Symbols are as in Fig. 2. Note that the scales of the Y-axis are not consistent

3 between the sites.

4 
1 Osono Fig. 1

2

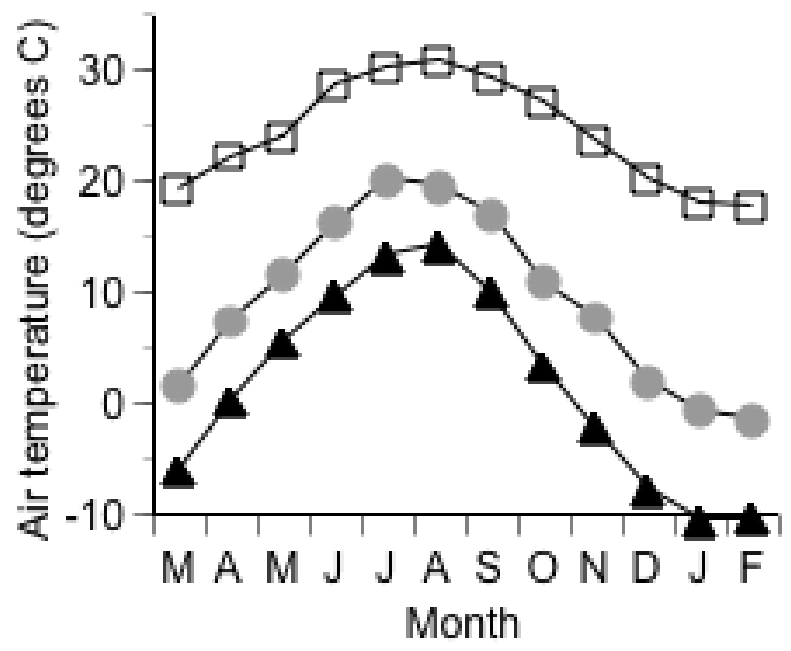


1 Osono Fig. 2

2

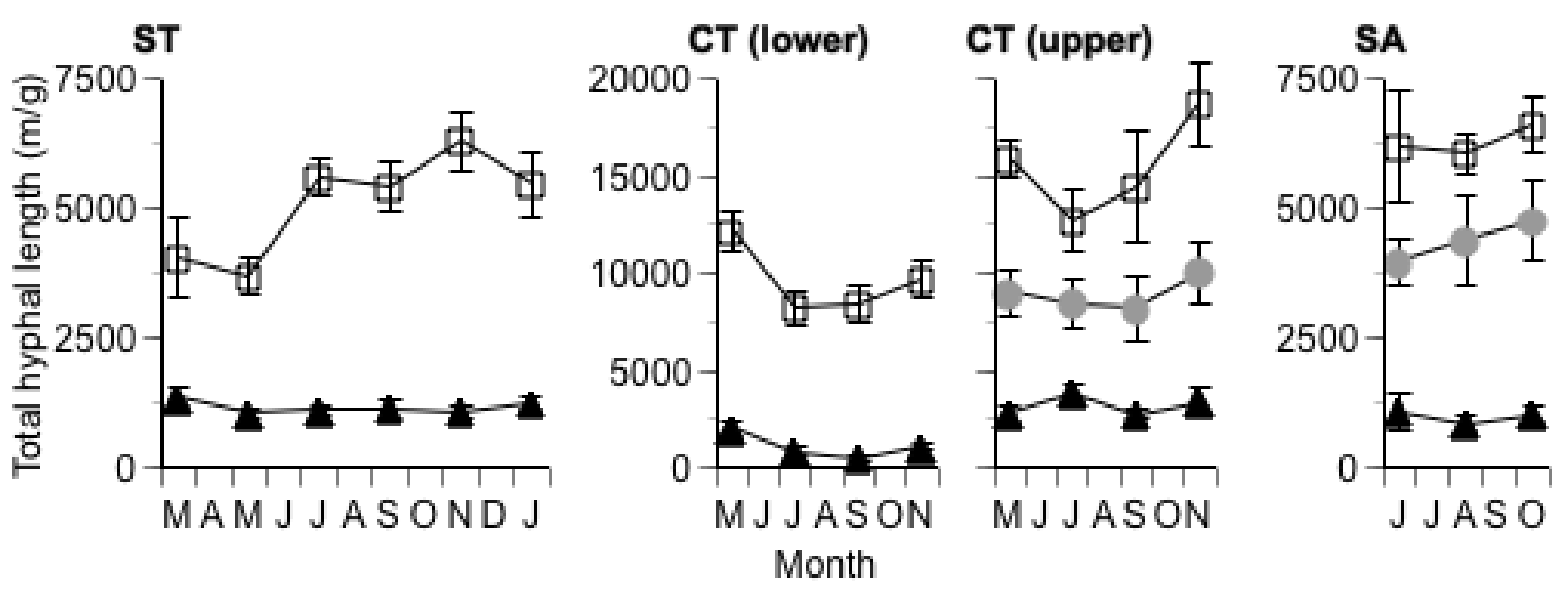


1 Osono Fig. 3

2
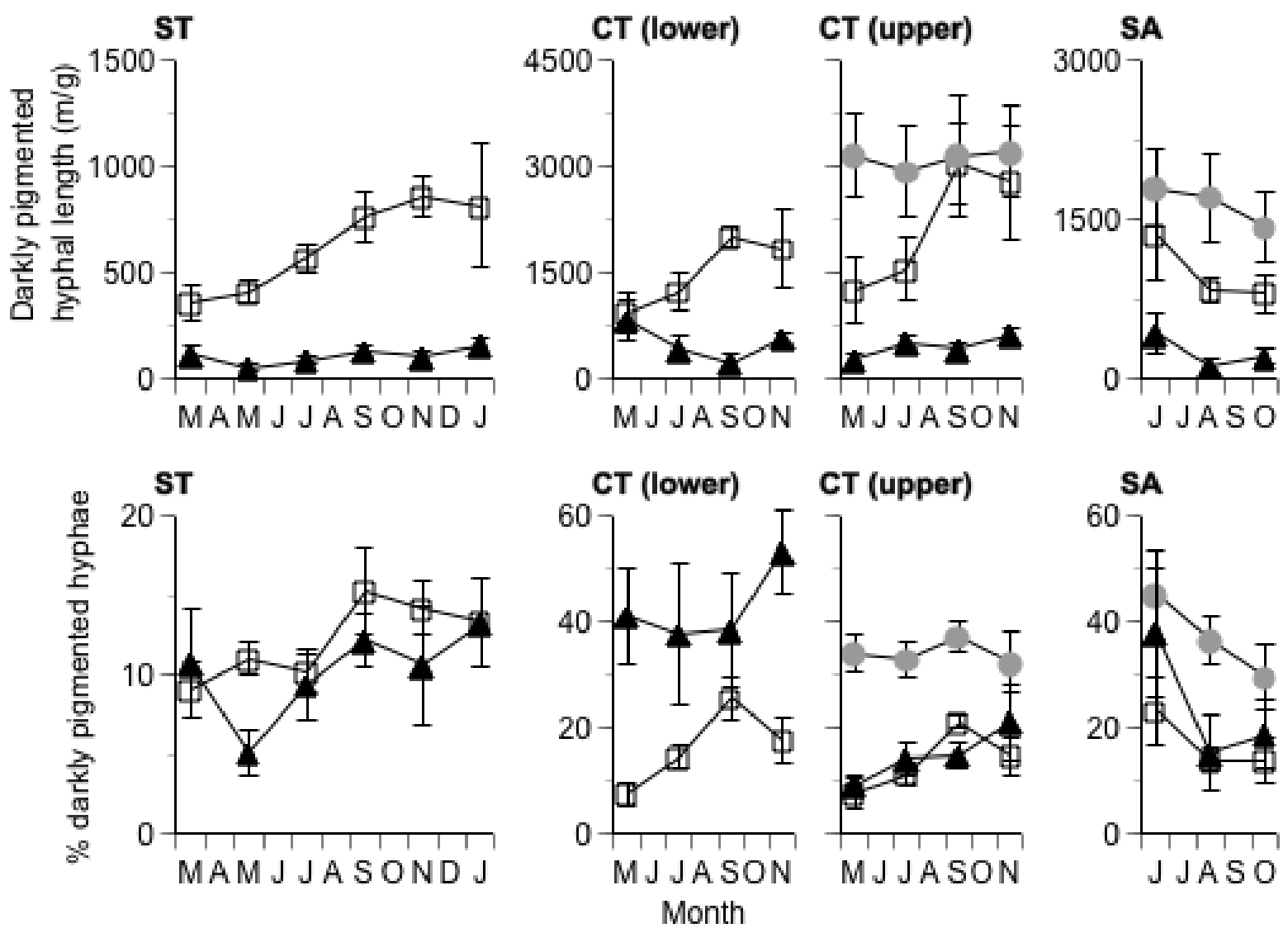
1 Osono Fig. 4
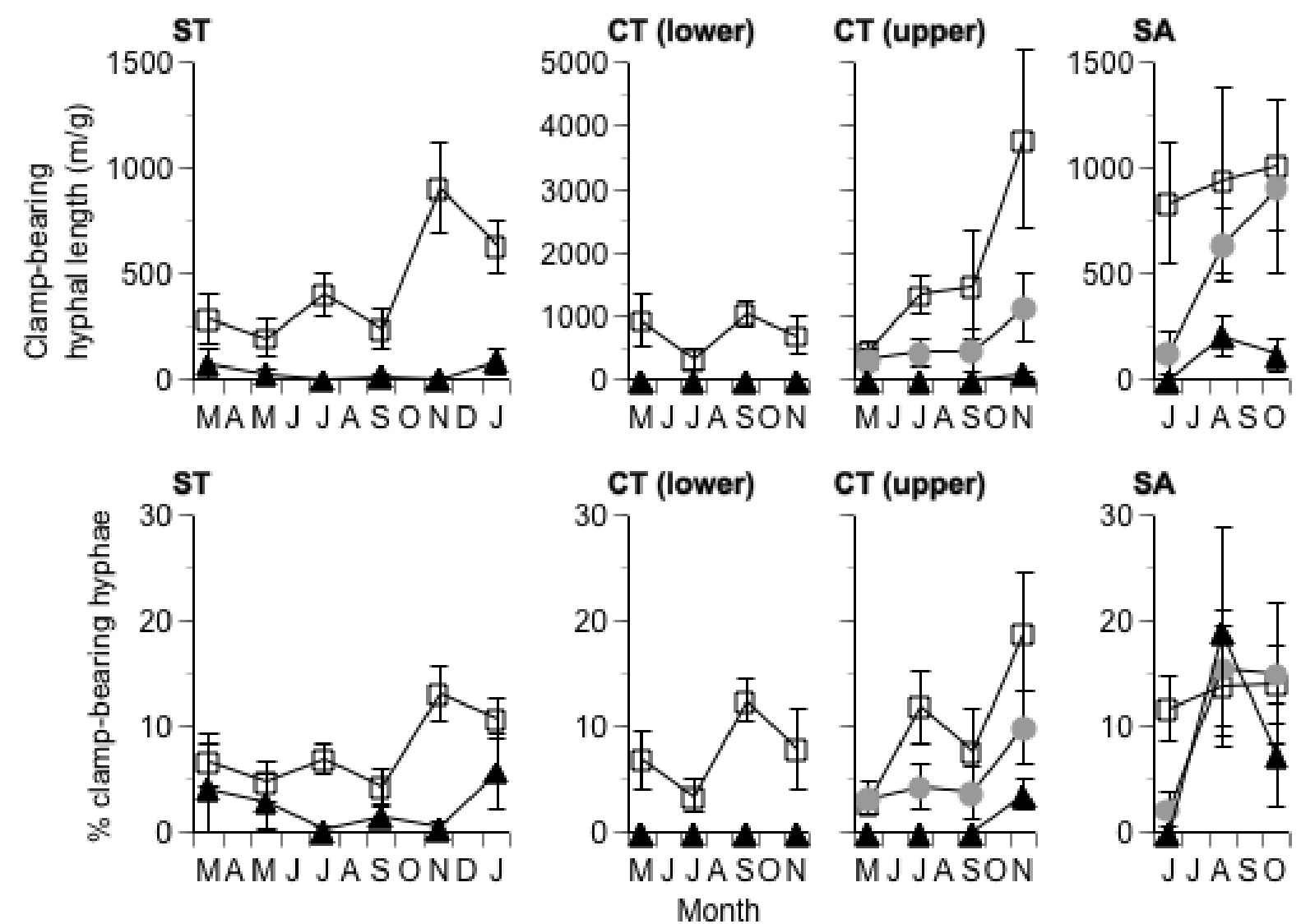
Osono Table 1

Table 1. Location, climate, vegetation, and properties of the forest floor in the study sites.

\begin{tabular}{|c|c|c|c|}
\hline Site ID & $\mathrm{ST}$ & $\mathrm{CT}$ & SA \\
\hline \multicolumn{4}{|l|}{ Location } \\
\hline Latitude N & $26^{\circ} 49^{\prime}$ & $35^{\circ} 18^{\prime}$ & $35^{\circ} 56^{\prime}$ \\
\hline Longitude E & $128^{\circ} 50^{\prime}$ & $135^{\circ} 43^{\prime}$ & $137^{\circ} 28^{\prime}$ \\
\hline Elevation $(\mathrm{m})$ & 330 & 660 & 2050 \\
\hline Site & Kunigami, Okinawa & Ashiu, Kyoto & Mt. Ontake, Gifu \\
\hline \multicolumn{4}{|l|}{ Climate } \\
\hline $\begin{array}{l}\text { Mean annual } \\
\text { temperature }\left({ }^{\circ} \mathrm{C}\right)\end{array}$ & $22^{\mathrm{a}}$ & $10^{\mathrm{b}}$ & $2^{\mathrm{c}}$ \\
\hline $\begin{array}{l}\text { Annual } \\
\text { precipitation }(\mathrm{mm})\end{array}$ & $2456^{\mathrm{a}}$ & $2495^{b}$ & $2500^{c}$ \\
\hline \multicolumn{4}{|l|}{ Vegetation } \\
\hline Type & $\begin{array}{l}\text { Evergreen } \\
\text { broad-leaved }\end{array}$ & $\begin{array}{l}\text { Deciduous } \\
\text { broad-leaved }\end{array}$ & Evergreen coniferous \\
\hline $\begin{array}{l}\text { Dominant } \\
\text { tree species }\end{array}$ & $\begin{array}{l}\text { Castanopsis sieboldii, } \\
\text { Schima wallichii }\end{array}$ & $\begin{array}{l}\text { Fagus crenata, } \\
\text { Quercus crispula }\end{array}$ & $\begin{array}{l}\text { Abies mariesii, A. veitchii, } \\
\text { Picea jezoensis var. hondoensis, } \\
\text { Betula ermanif }\end{array}$ \\
\hline \multicolumn{4}{|l|}{ Forest floor } \\
\hline Humus type & Mull & $\begin{array}{l}\text { Mull (lower), } \\
\text { Moder (upper)g }\end{array}$ & Moder \\
\hline Depth of L layer $(\mathrm{cm})^{\mathrm{i}}$ & $1.1 \pm 0.1 \mathrm{~b}$ & $1.2 \pm 0.1 \mathrm{~b}$ & $2.7 \pm 0.3 \mathrm{a}$ \\
\hline Depth of F layer $(\mathrm{cm})^{\mathrm{i}}$ & $1.0 \pm 0.2 \mathrm{c}$ & $4.0 \pm 0.4 \mathrm{~b}$ & $13.4 \pm 1.2 \mathrm{a}$ \\
\hline \multicolumn{4}{|c|}{ 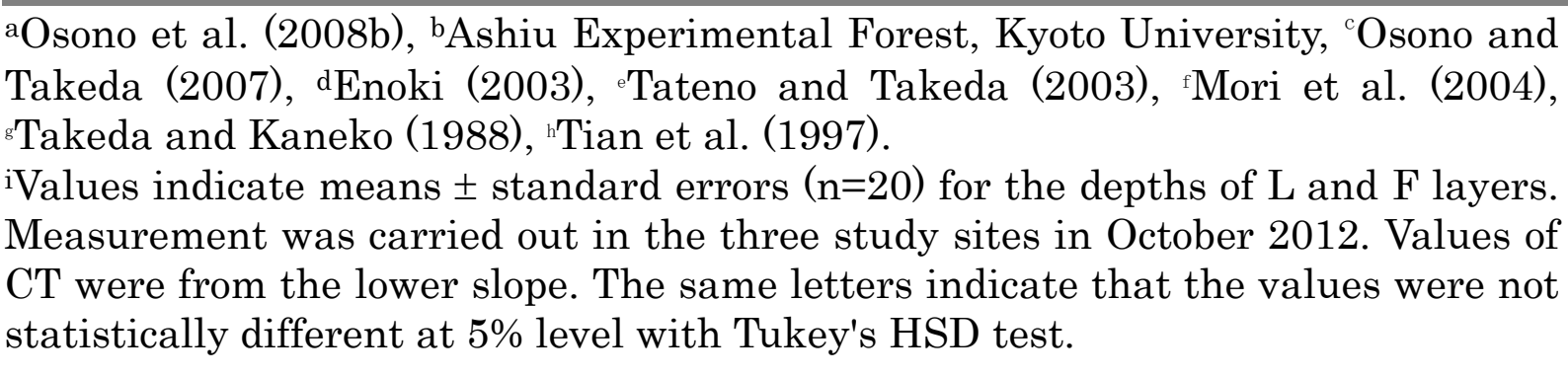 } \\
\hline
\end{tabular}


Osono Table 2

Table 2. Summary of generalized linear models for hyphal length. $\chi^{2}$ values are indicated. *** $\mathrm{P}<0.001, * * \mathrm{P}<0.01,{ }^{*} \mathrm{P}<0.05$, ns not significant.

\begin{tabular}{|c|c|c|c|c|c|c|c|c|}
\hline & \multicolumn{2}{|c|}{ Model } & \multicolumn{2}{|c|}{ Layer } & \multicolumn{2}{|c|}{ Month } & \multicolumn{2}{|c|}{ Layer $\times$ Month } \\
\hline \multicolumn{9}{|c|}{ Total hyphal length } \\
\hline $\mathrm{ST}$ & 165.0 & $* * *$ & 155.7 & $* * *$ & 15.7 & $* *$ & 17.5 & $* *$ \\
\hline CT (lower) & 88.3 & $* * *$ & 84.9 & $* * *$ & 16.7 & $* * *$ & 4.9 & $\mathrm{~ns}$ \\
\hline CT (upper) & 82.3 & $* * *$ & 78.9 & $* * *$ & 5.6 & $\mathrm{~ns}$ & 6.1 & $\mathrm{~ns}$ \\
\hline SA & 79.4 & $* * *$ & 78.8 & $* * *$ & 0.8 & $\mathrm{~ns}$ & 0.6 & $\mathrm{~ns}$ \\
\hline \multicolumn{9}{|c|}{ Darkly pigmented hyphal length } \\
\hline ST & 79.6 & $* * *$ & 65.7 & $* * *$ & 14.4 & * & 9.8 & $\mathrm{~ns}$ \\
\hline CT (lower) & 28.4 & $* * *$ & 20.5 & $* * *$ & 2.6 & ns & 9.6 & $*$ \\
\hline CT (upper) & 45.9 & $* * *$ & 40.4 & $* * *$ & 4.3 & $\mathrm{~ns}$ & 5.7 & $\mathrm{~ns}$ \\
\hline $\mathrm{SA}$ & 37.1 & $* * *$ & 34.0 & $* * *$ & 3.4 & ns & 1.1 & $\mathrm{~ns}$ \\
\hline \multicolumn{9}{|c|}{$\%$ darkly pigmented hyphae } \\
\hline ST & 15.3 & $\mathrm{~ns}$ & 2.3 & ns & 9.9 & ns & 3.7 & ns \\
\hline CT (lower) & 23.3 & $* *$ & 20.9 & $* * *$ & 3.0 & ns & 3.1 & ns \\
\hline CT (upper) & 68.6 & $* * *$ & 61.9 & $* * *$ & 9.4 & * & 7.8 & $\mathrm{~ns}$ \\
\hline $\mathrm{SA}$ & 22.5 & $* *$ & 13.4 & $* *$ & 8.8 & * & 1.8 & ns \\
\hline \multicolumn{9}{|c|}{ Clamp-bearing hyphal length } \\
\hline ST & 75.8 & $* * *$ & 48.6 & $* * *$ & 20.5 & $* *$ & 21.4 & $* * *$ \\
\hline CT (lower) & 26.6 & $* * *$ & 21.7 & $* * *$ & 4.0 & ns & 4.0 & $\mathrm{~ns}$ \\
\hline CT (upper) & 38.8 & $* * *$ & 21.7 & $* * *$ & 12.6 & $* *$ & 11.9 & ns \\
\hline SA & 20.2 & $* *$ & 15.4 & $* * *$ & 3.4 & $\mathrm{~ns}$ & 2.3 & $\mathrm{~ns}$ \\
\hline \multicolumn{9}{|c|}{ \% Clamp-bearing hyphae } \\
\hline ST & 31.0 & $* *$ & 16.5 & $* * *$ & 8.7 & ns & 8.4 & $\mathrm{~ns}$ \\
\hline CT (lower) & 32.2 & $* * *$ & 25.3 & $* * *$ & 6.3 & ns & 6.3 & $\mathrm{~ns}$ \\
\hline CT (upper) & 41.7 & $* * *$ & 23.7 & $* * *$ & 18.2 & $* * *$ & 7.8 & $\mathrm{~ns}$ \\
\hline $\mathrm{SA}$ & 12.2 & ns & 1.2 & ns & 7.7 & $*$ & 3.8 & ns \\
\hline
\end{tabular}




\section{Electronic Supplementary Material}

\section{Hyphal length in the forest floor and soil of subtropical, temperate, and subalpine forests}

Takashi Osono

S1. A review of hyphal length in forest and tundra litter examined with the same direct observation method. MAT, mean annual temperature; AP, annual precipitation. na, not available. Numbers in parentheses are the proportions relative to the total hyphal length.

\begin{tabular}{|c|c|c|c|c|c|c|c|c|c|c|}
\hline Location & Climate & MAT & AP & Vegetation & Tree species & Sample & Total hyphal & Darkly pigmented & Clamp-bearing & Ref. \\
\hline & & ${ }^{\circ} \mathrm{C}$ & $\mathrm{mm}$ & & & & length m/g & hyphal length m/g & hyphal length & \\
\hline & & & & & & & & & $\mathrm{m} / \mathrm{g}$ & \\
\hline Kyoto, Japan & Cool temperate & 10 & 2495 & Deciduous broad-leaved & Fagus crenata & Litter & 7867 & $983(12)$ & 410 ( 5) & 1 \\
\hline Shiga, Japan & Warm temperate & 15 & 1475 & Cypress plantation & Chamaecyparis obtusa & L layer & 12334 & $5800(42)$ & $1191(10)$ & 2 \\
\hline \multirow[t]{4}{*}{ Kyoto, Japan } & Warm temperate & 15 & 1734 & Secondary & Chamaecyparis obtusa & Litter & 7595 & $970(13)$ & 79 ( 1$)$ & 3 \\
\hline & & & & & & L2 layer & 12523 & 2943 (24) & $560(4)$ & \\
\hline & & & & & & F layer & 9549 & 2805 (29) & 119 ( 1$)$ & \\
\hline & & & & & & H layer & 6932 & 2546 (37) & 167 ( 2$)$ & \\
\hline Kyoto, Japan & Cool temperate & 10 & 2495 & Deciduous broad-leaved & Swida controversa & Litter & 5309 & 925 (16) & 111 ( 2 ) & 4 \\
\hline Kyoto, Japan & Warm temperate & 15 & 1581 & Secondary & Camellia japonica & Litter & 7824 & 998 (13) & 136 ( 2) & 5 \\
\hline
\end{tabular}




\begin{tabular}{|c|c|c|c|c|c|c|c|c|c|c|}
\hline Kyoto, Japan & Warm temperate & 15 & 1734 & Secondary & Chamaecyparis obtusa & Litter & 12321 & 3622 (29) & 154 ( 1$)$ & 6 \\
\hline & & & & Pine plantation & Pinus pentaphylla & Litter & 10385 & 1337 (13) & 336 ( 3) & \\
\hline Okinawa, Japan & Subtropical & 22 & 2456 & Evergreen broad-leaved & Castanopsis sieboldii & Litter & 6593 & 525 ( 9) & 556 ( 8) & 7 \\
\hline Chiang Rai, Thailand & Tropical seasonal & 25 & 1155 & Dry dipterocarpus & Shorea obtusa & Litter & 2738 & $551(19)$ & $80(2)$ & 8 \\
\hline Kyoto, Japan & Cool temperate & 10 & 2495 & Deciduous broad-leaved & Fagus crenata & L layer & 6927 & 1001 (13) & na & 9 \\
\hline \multirow[t]{2}{*}{ Nunavut, Canada } & Arctic & -20 & 64 & Tundra & Hylocomium splendens & Moss & 4446 & $1859(41)$ & 658 (13) & 10 \\
\hline & & & & & Racomitrium lanuginosum & Moss & 1164 & $349(30)$ & 107 ( 5) & \\
\hline Nunavut, Canada & Arctic & -20 & 64 & Tundra & Salix arctica & Litter & 4068 & $1063(30)$ & 145 ( 2$)$ & 11 \\
\hline \multirow[t]{3}{*}{ Nagano, Japan } & Cool temperate & & & Grassland & Miscanthus sinensis & Litter & 4720 & $395(10)$ & 155 ( 3$)$ & 12 \\
\hline & & & & Secondary coniferous & Pinus densiflora & Litter & 10273 & $1933(20)$ & $1454(14)$ & \\
\hline & & & & Deciduous broad-leaved & Quercus crispula & Litter & 3775 & $490(15)$ & 320 ( 9) & \\
\hline \multirow[t]{2}{*}{ Okinawa, Japan } & Subtropical & 22 & 2456 & Evergreen broad-leaved & Castanopsis sieboldii & L layer & 5092 & $630(12)$ & 444 ( 8) & 13 \\
\hline & & & & & & A layer & 1175 & $110(10)$ & 36 ( 3$)$ & \\
\hline \multirow[t]{5}{*}{ Kyoto, Japan } & Cool temperate & 10 & 2495 & Deciduous broad-leaved & Fagus crenata (mull) & L layer & 8514 & $1603(22)$ & 627 ( 7) & \\
\hline & & & & & & A layer & 1139 & $510(41)$ & $0(0)$ & \\
\hline & & & & & Fagus crenata (moder) & L layer & 15473 & $2154(14)$ & $1761(10)$ & \\
\hline & & & & & & F layer & 8949 & 3118 (34) & 585 ( 5) & \\
\hline & & & & & & A layer & 3242 & $451(15)$ & $22(1)$ & \\
\hline \multirow[t]{3}{*}{ Gifu, Japan } & Subalpine & 2 & 2500 & Evergreen coniferous & Abies spp., Betula ermanii & L layer & 6289 & 1004 (17) & 929 (13) & \\
\hline & & & & & & F layer & 4382 & 1649 (37) & $559(11)$ & \\
\hline & & & & & & A layer & 998 & $255(24)$ & 109 ( 9) & \\
\hline
\end{tabular}


Reference. 1, Osono and Takeda (2001); 2, Data of control site, Osono et al. (2002); 3, Osono et al. (2003); 4, means for sterilized and unsterilized litter, Osono (2005); 5, means for bleached and nonbleached portions, Koide et al. (2005); 6, means for four treatments, Osono et al. (2006); 7, means for bleached and nonbleached portions, Osono et al. (2008b); 8, Osono et al. (2009); 9, data of nonbleached litter, Osono et al. (2011); 10, means for horizontal layers, Osono et al. (2012); 11, Osono et al. (2014); 12, Hobara et al. (2014); 13, the present study. 

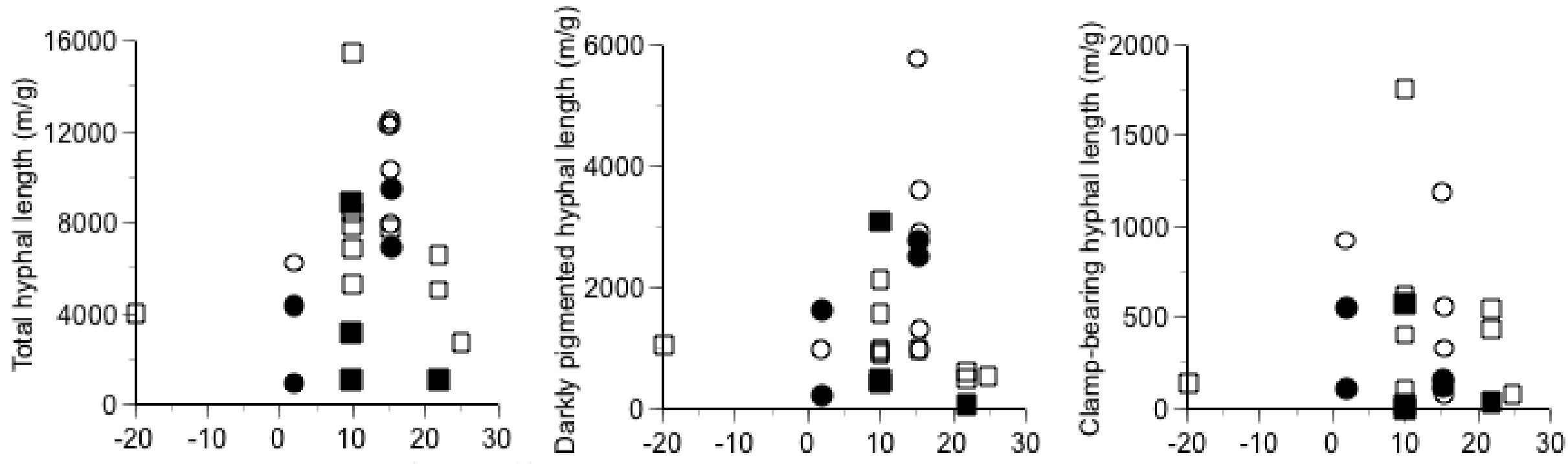

Mean annual temperature (degree C)
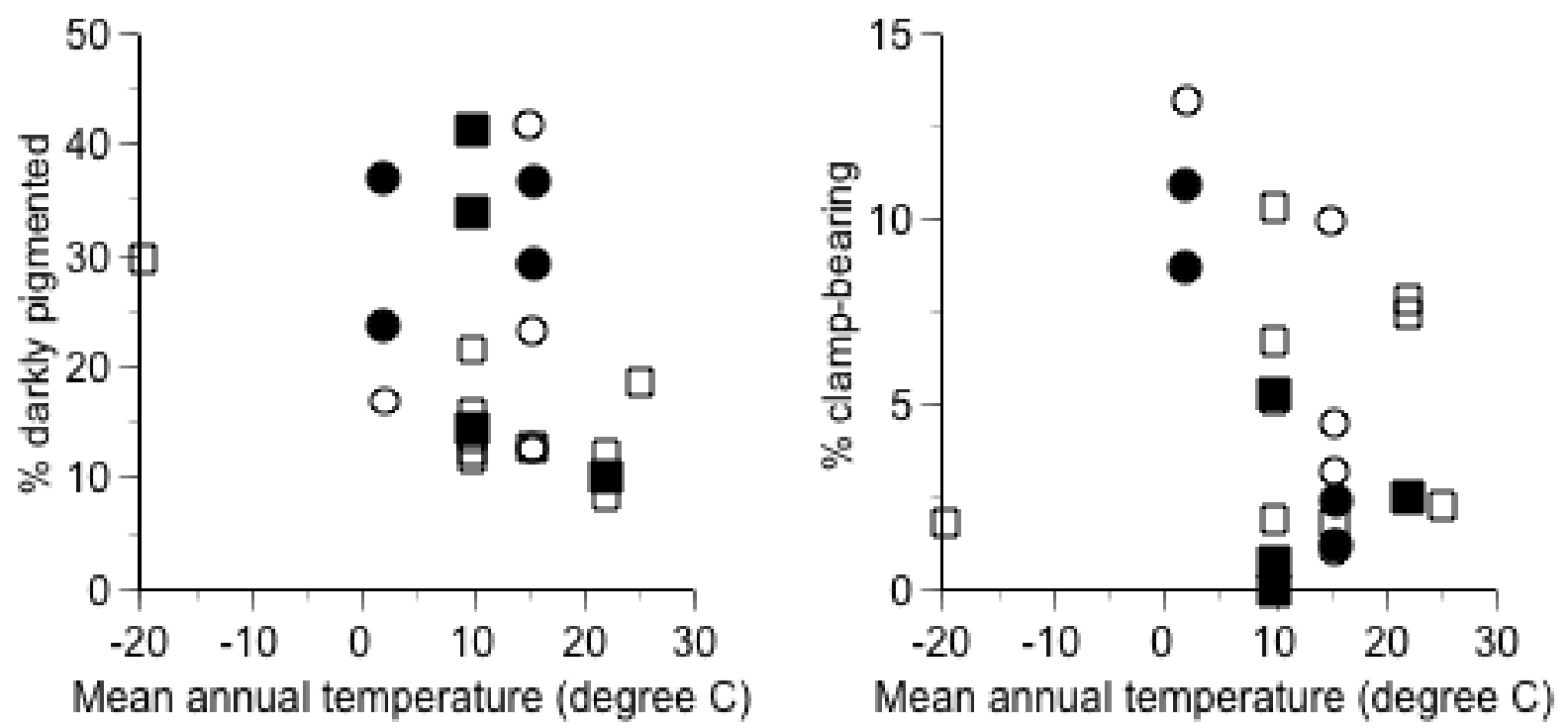

Fig. S1. Hyphal length plotted against mean annual temperature. Data are after Table S1. Data of arctic moss are not included. 